\title{
CELTI. Un municipio romano en la campiña sevillana
}

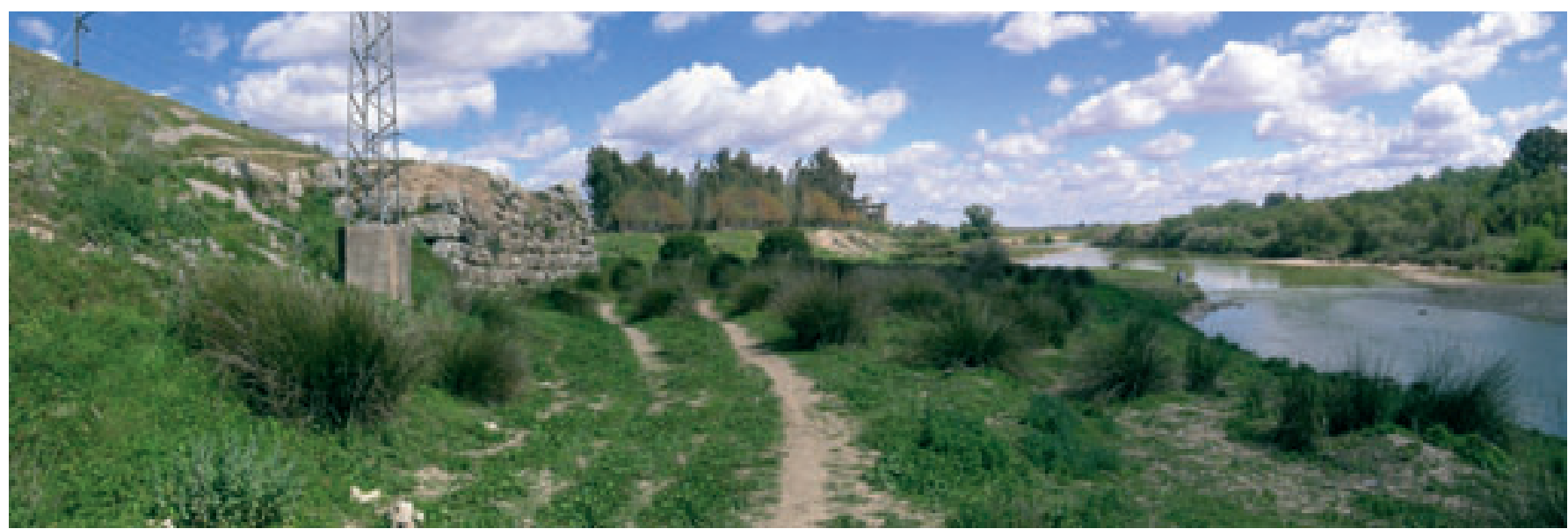

El Higuerón, estructura ciclópea a orillas e Guadalquivir, cuya cronología y funcionalidad concreta se desconoce. Foto: Juan Antonio Fernández Naranjo

En la antigüedad, al igual que en la actualidad, no en vano somos herederos del pasado, el último tramo de la margen derecha del río Guadalquivir estaba salpicado por multitud de asentamientos y ciudades. También entonces, primero el Tartessos, después el Baetis y finalmente el Al-wadi al-Kabir era fuente de vida, propiciaba recursos y constituía una vía de comunicación que posibilitaba las relaciones comerciales y permitía el contacto entre los habitantes del territorio. Ese territorio empezó a poblarse de forma estable entre los siglos IX y VIII a. C., cuando las poblaciones indigenas empezaron a buscar y asomarse a sus orillas para facilitar los contactos comerciales, especialmente activos tras la llegada de los fenicios al sur de la península ibérica.

Desde Córdoba hasta Coria del Río, donde se situaba la desembocadura, la margen derecha del Guadalquivir está repleta de yacimientos de mayor o menor entidad. Algunos, los mejor ubicados, llegaron a ser municipios romanos, todos ellos con puertos fluviales.

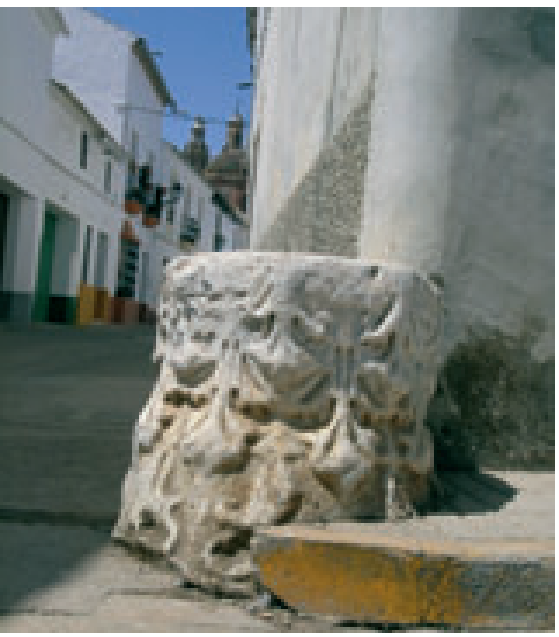

El Pelote, capitel romano de mármol usado como cantonera en la esquina entre las calles Nueva y Blancaflor. Foto: Juan Antonio Fernández Naranjo
Entre ellos Celti y junto a él otros tantos; tantos cómo pueblos en la actualidad. Si partiéramos de Corduba navegando río abajo buscando la desembocadura y el mar abierto para adentrarnos en el Mediterráneo, siempre en la margen derecha, nos encontraríamos con Carbula (Almodóvar del Río), Detumo (Posadas?), Celti (Peñaflor), Axati (Lora del Río), Arva ("El CastiIlejo", en Alcolea de Río), Canama (Alcolea del Río), Naeva (Cantillana), Ilipa Magna (Alcalá del Río), Italica (Santiponce), Hispalis (Sevilla), Osset (San Juan de Aznalfarache) y Caura (Coria del Río).

La situación de Celti se eligió para garantizar y jugar un papel dominante en la vida económica, social, política y cultural en el bajo valle del río. Ocupaba un punto intermedio entre Corduba (la capital de la provincia) e Hispalis, a cuyo conventus pertenecia. Su ubicación física no era caprichosa, ya que se buscó una elevación topográfica destacada en una encrucijada de caminos próxima a la desembocadura del Genil (Singilis) en el Guadalquivir, lo que le permitía el contacto con Astigi (Écija) y desde aqui hacia la sierra subbetica y la parte más oriental de la provincia, donde nace el Genil -Sierra Nevada-. También a través de Astigi accedía a la Vía Augusta (Nacional IV), que reforzaba sus relaciones comerciales terrestres con otras ciudades, como Carmo (Carmona) y Obulcula (Castillo de la Monclova, en Fuentes de Andalucía). Ambas vías de comunicación envolvian un territorio, la actual campiña, que era aprovechada por los citados municipios romanos para la explotación agrícola (vid, olivo y cereal) y ganadera (cabra, oveja y cerdo).

Completando la explotación de esos recursos, hacia el norte, y ahora por vía terrestre, una serie de pasos naturales permitian la conexión con Sierra Morena, alcanzar el Guadiana (Anas) y la capital lusitana (Emerita Augusta). A través de ellos también conectaban con las ricas reservas de metales de la región, que se encontraban bastante más al Oeste (norte de Huelva) y hacia el Este (cerca de Córdoba). Finalmente, también con zonas de laboreo minero más próximos, como los existentes en la actual Puebla de los Infan- tes, de donde extraerian cobre, oro y plata; y también las gestionadas por el municipio flavio de Muniqua (Villanueva del Río y Minas), desde donde se explotaba la falla minera de El Pedroso, rica en hierro, cobre y el oro cautivo que éste suele llevar asociado.

Frente a la fuerte carga simbólica e historiográfica que desde antiguo rodeó a Italica, Corduba o Hispalis, la difusión arqueológica de estos municipios romanos que se asoman al rio fue mucho más reciente y residual, aunque ya eran conocidos por los humanistas e ilustrados que manejaban las fuentes antiguas y se interesaban por la epigrafia y la numismática. No se generalizará hasta fines del siglo $X_{I}$, al igual que la de cualquier otro yacimiento del país, cuando se interesaron y establecieron en el sur peninsular extranjeros como G. Bonsor, A. Engel, P. París, o A M. Huntington, que colaborando con los arqueólogos locales publicaron en sus lenguas vernáculas los hallazgos que se producian. Unos, como el joven pintor G. Bonsor, lo hicieron atraídos por el pintoresquismo que relataban los libros de viajes y otros siguiendo las huellas del epigrafista alemán Emil Hübner, que en 1869 había publicado el volumen de CIL dedicado a Hispania. La epigrafía junto con la numismática sirvió para identificar las ciudades citadas en las fuentes clásicas, que en el caso de Celti son en Plinio el Viejo (HN3, 11), en el Itinerario Antonio (It. 414,5), en el Cosmógrafo de Rávena (Rav. IV. 44 315.2), o en el II Concilio Hispalense del año 619.

Conocida la epigrafía y las monedas con la leyenda Celtitan, las primeras descripciones que demostraban el potencial arqueológico del yacimiento se deben a George Bonsor, quien desde Carmona y Mairena del Alcor visitó y colaboró en la investigación de todos los grandes yacimientos de la Baja Andalucia (Carmona, Los Alcores, Bolonia, Itálica, etc.). Aceptada desde antiguo la identificación de Celti con Peñaflor, G. Bonsor describió los restos ciclópeos de "El Higuerón", un columbario familiar en el "Cortinal de las Cruces", ataúdes de plomo, restos de edificaciones en "Pared Blanca", el trazado del acueducto y hornos cerámicos de ánforas. 
Curiosamente, valorada la explotación aceitera de la Bética y su comercialización por el Imperio y en especial con la gran metrópoli (M. Ponsich, L. Abad, G. Chic y J. Remesal), tras un leve balbuceo arqueológico emprendido por el Museo Arqueológico Provincial y la Delegación Provincial de la Consejería de Cultura en la década de 1980, será otro extranjero quién se interese por Celti.

Entre 1987 y 1992, al frente de un nutrido equipo de investigadores británicos con colaboradores locales, el arqueólogo hispanista Simon Keay dirigió un Proyecto General de Investigación en Celti (Peñaflor) (KEAY et ál., 2001). Gran conocedor e interesado en los procesos de romanización en su relación con los pueblos indigenas, tras las experiencias de la Tarraconense, centró sus intereses en este municipio romano. Con los precedentes y estado de la investigación, durante cinco años planteó intervenciones arqueológicas con el fin de dar respuesta a una serie de cuestiones relacionadas con el yacimiento, su evolución y papel desempeñado durante el proceso de romanización del sur peninsular.

Entre otros objetivos interesaba saber la fecha en que el yacimiento adquirió el carácter urbano y las posibles relaciones con los coetáneos yacimientos fenicios y cartagineses. También el impacto de Roma en la ciudad tras la conquista del sur de Hispania, la romanización de la ciudad durante los últimos momentos de la República e inicios del Imperio, o el papel desempeñado por la ciudad en la economía de la provincia, especialmente con respecto a la producción y exportación de aceite de oliva en ánforas Dressel 20. Todo ello reforzado por un minucioso estudio de la epigrafía celtitana.

Los resultados obtenidos, sumados al estado general de la investigación histórica y arqueológica, permiten afirmar que en el valle del Guadalquivir el patrón de asentamiento romano no se establece firmemente hasta mediados o fines del siglo I a. C. Con anterioridad a estas fechas, los centros de poder romano tan sólo habian quedado establecidos en Italica y en Corduba. A partir de ese momento, tras la conclusión de las guerras civiles, Cesar y Augusto establecieron en el valle del Guadalquivir y tierras adyacentes una serie de colonias como Hispalis (Sevilla), Astigi (Ecija), Urso (Osuna), Corduba (Córdoba), Itucci (Torreparedones?, Córdoba), Ucubi (Espejo) y Tucci (Martos). Estas colonias, junto con otras ciudades nativas a las que se les concedió el estatuto municipal, fueron conectadas por una red viaria y agrupadas en cuatro distritos judiciales: los concentus hispalensis, cordubensis, gaditanus y astigianus. Todo ello en el marco de la recién creada provincia Hispania Ulterior Baetica, con capital en Corduba. Pese a ello, el número total de nuevas ciudades romanas y las nativas romanizadas era todavia bajo en comparación con la mayoría de los asentamientos de la región, cuya población debió mantenerse inicialmente ajena a esos cambios. El análisis de los datos arqueológicos relativos a la formación de paisajes urbanos y la construcción de edificios públicos a la romana sugiere que esa transformación no se produjo hasta fines del siglo I d. C., en gran medida debido a la decisión política dada por los emperadores flavios de concederle el ius latii a todas las comunidades de la provincia.

Esa transformación está bien documentada en $\mathrm{Mu}$ nigua y también en Celti, ya que de este momento datan los epígrafes más antiguos y también algunos edificios del foro. Desde este momento hasta el siglo III d. C., esa epigrafia nos habla de una serie de familias celtitanas, como los Fabii, Aelii, Aemilii, Annii, Brutii, Caesii, Fulvii, Licinii, Lurii o los Sempronii, que sin descartar la explotación de productos de distribución más local y si olvidar el vino se lucraban, al igual que otras familias de los vecinos municipios, con la producción y la comercialización del aceite de

Mausoleo romano labrado en la roca, posteriormente reutilizado como Capilla de los Santos Mártires. Planta-Sección. Dibujo: Juan Antonio Fernández Naranjo

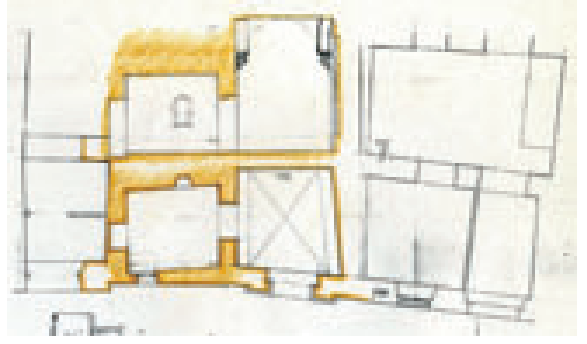

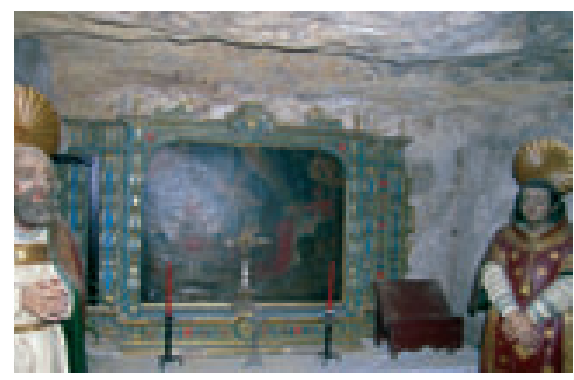

Mausoleo romano labrado en la roca, posteriormente reutilizado como Capilla de los Santos Mártires Críspulo y Restituto.

Foto: Juan Antonio Fernández Naranio

oliva. En el territorio de las ciudades citadas, a orillas del Genil y Guadalquivir, se han localizado más de un centenar de yacimientos que en su día se dedicaron a la manufactura de ánforas para el transporte del aceite, que finalmente se canalizaba y difundia por todo el Imperio a través del puerto de Hispalis, hasta que a mediados del siglo III d. C. la Bética dejó de ser el principal proveedor de aceite de Roma y las fronteras.

Desde esos momentos y hasta el siglo VII, con los profundos cambios administrativos políticos y económicos sufridos por la Bética, este municipio, al igual que otras ciudades de las provincias periféricas, quedó marginado y especialmente perjudicado cuando a principios del siglo IV Corduba dejó de ser la capital de la diócesis hispaniorum en favor de Emérita Augusta. Poco después, desde principios del siglo $V$, la arqueología documenta una gran ruptura y desintegración de la estructura urbana que generó un nuevo paisaje urbano, que coincide con el momento en que el control romano pasó a manos de vándalos, suevos y visigodos, aunque es mucho lo que queda por investigar. Pese a ello, reconociéndose el potencial arqueológico de Celti y sus valores patrimoniales, el yacimiento fue declarado BIC, con la categoría de Zona Arqueológica, el 18 de enero de 1994.

José Manuel Rodríguez Hidalgo

Delegación Provincial de Cultura de Sevilla

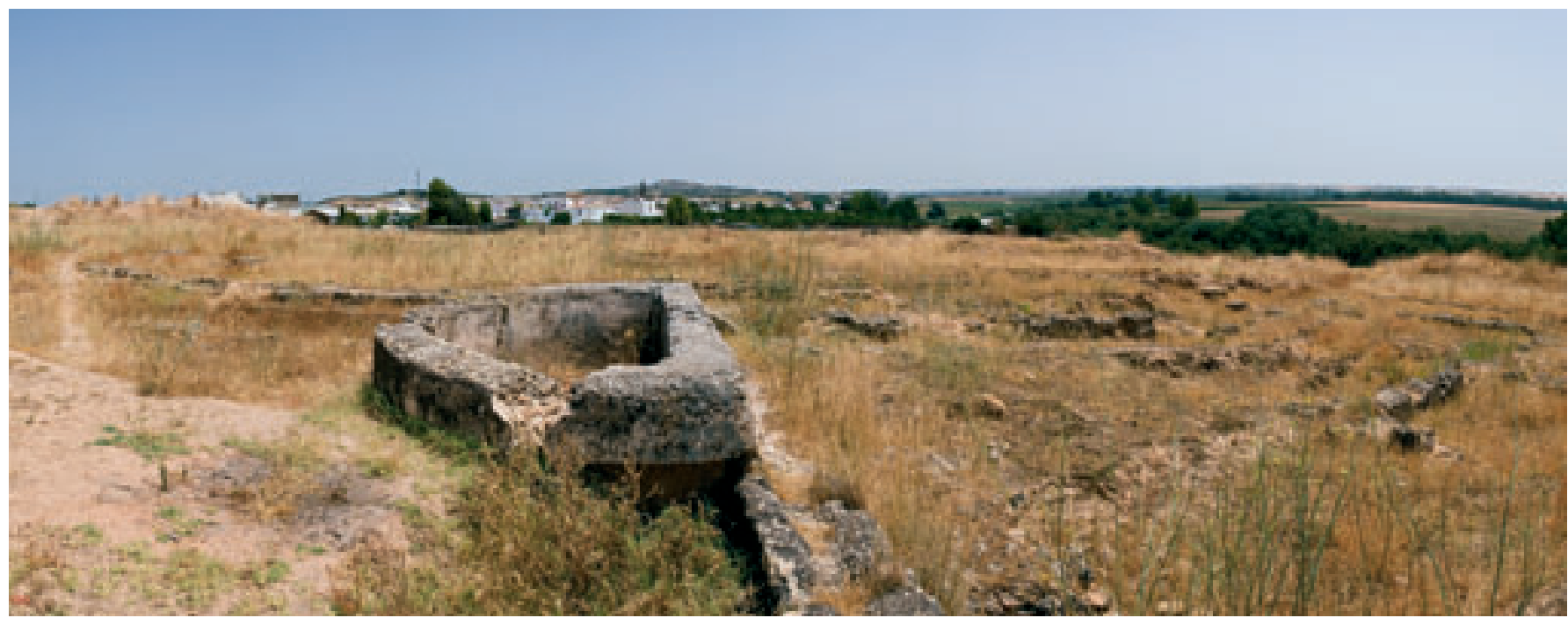

Restos del área forense de Celti en La Viña (Peñaflor, Sevilla). Foto: Juan Carlos Cazalla, IAPH 